\title{
La Cote-Saint-André
}

Le Rival

Denis Gonin

\section{(2) OpenEdition}

\section{Journals}

Édition électronique

URL : http://journals.openedition.org/adlfi/1825

ISSN : 2114-0502

Éditeur

Ministère de la culture

Référence électronique

Denis Gonin, « La Cote-Saint-André », ADLFI. Archéologie de la France - Informations [En ligne], RhôneAlpes, mis en ligne le 01 mars 2008, consulté le 20 avril 2019. URL : http://journals.openedition.org/ adlfi/1825

Ce document a été généré automatiquement le 20 avril 2019.

(C) Ministère de la Culture et de la Communication, CNRS 


\title{
La Cote-Saint-André
}

\author{
Le Rival
}

\section{Denis Gonin}

\section{Identifiant de l'opération archéologique : 9748}

Date de l'opération : 2008 (PI)

Une prospection pédestre préalable à l'implantation d'une ZAC, a été réalisée dans la plaine de la Bièvre au sud de La Côte-Saint-André aux mas du « Rivalet la gare » et des "Olagnières-Sud ».

2 La plaine de La Côte-Saint-André ou, plus généralement de la Bièvre, est un lit d'ancien glacier. Elle garde les traces de plusieurs glaciations et est constituée d'alluvions fluvioglaciaires et fluviatiles. Elle se situe entre Grenoble et Vienne, commence à Beaucroissant et débouche en pente douce sur la plaine de la Valloire à l'ouest, au niveau de Beaufort. $\mathrm{Au}$ nord se situe la plaine du Liers. La plaine de la Bièvre a un réseau hydrographique réduit au minimum. Un seul cours d'eau traverse la plaine d'est en ouest : le Rival.

Le village est situé au pied d'une pente constituée de colluvions. C'est sur cette commune qu'avait été découvert, en 1888, le char de bronze exposé au musée de la civilisation galloromaine de Lyon. Malheureusement le lieu précis a depuis, été oublié. Il est toutefois vers cette future ZAC.

Une recherche documentaire a permis de situer le mas de la découverte : mas de Garchat. Une relecture des textes d'Ernest Chantre, de Joseph Déchelette et de Gabriel Chapotat a permis de déduire l'existence de trois tumuli.Les positions de ces derniers sont retrouvées grâce à des superpositions de cadastres et de photos aériennes.

Parallèlement à cette recherche, une prospection pédestre faite aux mas du « Rival et la gare » et des «Olagnières-Sud » a livré des fragments de tegulaeen faible quantité. Une vaste zone d'occupation apparaît avec de multiples concentrations couvrant une surface d'occupation importante dont l'interprétation en prospection reste délicate. Le mobilier céramique est peu présent mais nous renseigne quand même sur l'existence d'une occupation jusqu'au haut Moyen Âge. 
GONIN Denis (Chercheur bénévole)

INDEX

Thèmes : céramique

Index chronologique : Antiquité, haut Moyen Âge

Index géographique : Rhône-Alpes, Isère (38), Côte-Saint-André

operation Prospection inventaire (PI)

\section{AUTEUR}

DENIS GONIN

Chercheur bénévole 